Miscelánea Medieval Murciana. Vol. XIX-XX. Años 1995-1996. Págs. 233-244

\title{
EL ROMANCE DE TARQUINO Y LUCRECIA
}

\author{
Francisca Moya
}

\author{
A Pilar Sánchez Parra, una \\ mujer valiente, in memoriam.
}

O. La historia de Lucrecia, matrona romana que se dió la muerte tras haber sido violada, cuenta con tratamientos literarios muy felices en la literatura clásica latina, entre los que sobresalen el de Tito Livio y el ovidiano de Fastos'. El valor ejemplar de su suicidio y el haber sido éste causa desencadenante de la expulsión de los reyes -el violador era miembro de la monarquía de los Tarquinios ${ }^{2}-$ y la instauración de la República contribuyó sin duda al éxito de la historia. Livio la cuenta in extenso (I 5759), sirviendo de cierre al libro primero; Ovidio, al cantar las diferentes efemérides del mes de febrero se detiene, como era de esperar, en una fecha memorable que los romanos celebraban gustosos, el Regifugium ( $F$, II 721-852); el rey era, lógicamente, Tarquinio el Soberbio. Esta historia contenía una serie de ingredientes susceptibles de

1 Esta historia estaba ya en Fabio Pictor, según se deduce de Dioniso de Halicamaso IV 64; en una tragedia de Accio, de acuerdo con Cicerón Pro Sestio 123, que se cree la misma que Brurus, atribuida por Varrón, De lin. gua latina 6. 7. a "Cassio" (por Accio): luego la resumirá Valerio Máximo VI 1, etc.

2 Aunque el romance to llama "rey", tanto en Livio como en Ovidio se trata de Sexto Tarquinio, joven prín. cipe, hijo del rey Tarquinio el Soberbio. con todo, el apelativo "Soberbio" también lo ostenta, con razón, el hijo. Era primo de Tarquinio Colatino, esposo de Luerecia, y también de Junio Bruto, el que asume la venganza de la violación. 
tratamiento literario: la pasión incontrolable del joven Tarquinio, la pudicitia y fidelidad de Lucrecia a su esposo, la violencia de que es objeto la mujer, su confesión del hecho, el suicidio y la reacción de los que contemplan el espectáculo; la mezcla de historia y leyenda, de épica, elegía y tragedia favorecía el interés por ese tratamiento. Todo ello explica que el tema fuese recreado en todos los tiempos y de modos diversos. De cómo se fue efectuando la "seleccción de lo fundamental" habla el texto de Valerio Máximo ${ }^{3}$ o el epigrama de la Antologia latina ${ }^{4}$; los poemas latinos de la literatura medieval o los romances evidencian, por su parte, que la "historia" se incorporó a la literatura de manera semejante a los grandes temas de la leyenda troyana o de otros famosos mitos; en el mundo moderno no deja de estar presente en la literatura ${ }^{5}$, en la música ${ }^{6}, o$ en la pintura ${ }^{7}$.

1. El Romancero español, en concreto el romance que nos va a ocupar, es un ejemplo más del éxito y difusión de la historia, y de cómo, con las variantes lógicas e inherentes a cualquier transmisión oral, o tratamiento literario, la recreación mantiene los elementos fundamentales, siendo su escritura una interpretación, incluso fiel, de los textos. El romance, titulado Tarquino y Lucrecia, anónimo y que forma parte del Cancionero de Romances, dice así:

3 VI 1. Aparece como ejemplo de pudicitia, destacando V. Máximo el paso de la monarquía a la república. al imperium consulare: Dux Romanae pudicitiae Lucretiae, cuius virilis animus maligno errore fortunae muliebre corpus sortitus est, a Sex. Tarquinio regis Superbi filio per vim stuprum pati coacta, cum gravissimis verbis iniuriam suam in concilio necessariorum deplorasset, ferro se, quod veste tectum adiulerat, inseremit causamque tam animoso interitu imperium consulare pro regio permutandi populo Romano praebuit.

4 El epigrama trata de dejar claro que ella, es decir, su alma, no ha sido culpable; sólo su cuerpo ha sido mancillado, lo que también ponderaban los textos clásicos. En Anth. Lat. 900 así se lee: Roma, tibi ambiguum mea mors sine teste dedisset/_esset utrum ut corpus sic scelerata anima J Proin animam testor scelus haud setigisse, sed ecce. ut solum foedum est corpus, et id fodio, qua cruor inflictam labem lavet et per apertal pectora ab invisa sit fuga animae. ("Roma, a ti mi muene sin testigo te hubiese hecho dudar de si era mi alma, así como el cuerpo, culpable. Por eso testifico que el crimen no ha afectado a mi alma, pero he aquí que, al estar sólo mi cuerpo manchado, a él lo traspaso por donde la sangre pueda lavar la mancha infligida y por la abertura del pecho pueda mi alma huir de esta odiosa morada").

5 Amén de los latinos y medievales (tanto en latín como en lenguas vemáculas: of. por ej. la historia de Lucrecia en Le Roman de la Rose. vv. 8.859-8.620), la literatura modema siguí tratando el tema; así, el poema de W. Shakespeare, "Te rape of Lucrece" o las tragedias de Hans Sachs (s. XVI), Pierre Du Ryer (s. XVII), François Ponsard (s. XIX), etc. En España recordamos los sonetos de J. de Arguijo o J. Vicente Alonso, la tragedia de N. Fernández de Moratín, y de su éxito hablaba ya, además nuestro romance, uno jocoso de Quevedo, intitulado "Consulta el rey Tarquino a una dueña cerca de sus amores y ella le aconseja".

6 Por ejemplo, la cantata para soprano y címbalo de Georg Friedrich Händel.

7 Botticelli contó la historia completa en un tróptico (Boston. Gardner); a Lucrecia y Tarquinio lo representaron, entre otros. Tiziano (Viena), Tintoretto (Chicago). Luca Giordano Jordan (Louvre), Rubens (Potsdam): la muente de Lucrecia, Durero (Munich), L. Cranach (Munich), Rembrandt (Washington), P. Caliani, el Veronés. Luca Cambiaso (Prado), E. de Rosales (Casón del Buen Retiro), etc.

8 Cito por Romancero general, Biblioteca de Autores españoles, tomo X, Madrid 1945, p. 353 ("Romances concernientes a la historia de Roma"). 
Aquel rey de los romanos

Que Tarquino se llamaba,

Namoróse de Lucrecia

La noble y casta romana,

$5 \quad Y$ para dormir con ella

Una gran traición pensaba.

Vase muy secretamente

Adonde Lucrecia estaba.

Cuando en su casa lo vido,

10 Como á rey lo aposentaba:

A hora de media noche

Tarquino se levantaba;

Vase para su aposento,

Adonde Lucrecia estaba,

15 A la cual halló durmiendo,

De tal traición descuidada.

En llegando cerca d'ella

Desenvainó su espada,

Y á los pechos se la puso;

20 D'esta manera le habla:

- Yo soy aquel rey Tarquino

Rey de Roma la nombrada;

$\mathrm{El}$ amor que yo te tengo

Las entrañas me traspasa:

25 Si cumples mi voluntad

Serás rica y estimada,

Si no, yo te matare

Con esta cruel espada.

-Esto no haré yo, oh Rey,

30 Si la vida me costara;

Que mas la quiero perder

Que no vivir deshonrada.-

Como vido el rey Tarquino

Que la muerte no bastaba.

35 Acordó d'otra traición;

Con ella la amenazaba.

-Si no cumples mi deseo

Como yo te lo rogaba,

Yo te mataré, Lucrecia,

40 Con un negro de tu casa,

$Y$ desque muerto lo tenga

Echarlo he en la tu cama;

Yo dins por toda Roma

Que a ambos juntos os tomara.-

45 Despues qu'esto oyó Lucrecia,

Que tan gran traición pensaba,

Cumplióle su voluntad

Por no ser tan deshonrada.
Cuando Tarquino hubo hecho

50 Lo que tanto deseaba.

Muy alegre y muy contento

Para Roma se tomaba.

Lucrecia quedó muy uriste

En verse tan deshonrada:

Enviara muy aprisa

Con un siervo de su casa

A llamar a su marido,

Porque allá en Roma s'estaba.

Cuando ante sí lo vido,

60 D'esta manera le habla.

-¡Oh mi amado Colatino!

Ya es perdida la mi fama.

Que pisadas de hombre ajemo

Han hollado la tu cama.

65 El soberbio rey Tarquino

Vino anoche a tu posada;

Recibile como á rey.

$Y$ dejóme violada.

Yo me daré tal castigo

70 Como adúltera malvada,

Porque ninguna matrona

Por mi ejemplo sea mala.-

Estas palabras diciendo

Echa mano de una espada.

75 Que muy secreta traía

Debajo de la su halda,

Y a los pechos se la pone,

Que lástima era mirarla.

Luego alli en aquel momento

80 muerta cae la romana.

Su marido que la viera

Amargamente lloraba:

Sacóle de aquella herida

Aquella sangrienta espada,

$85 Y$ en su mano la tenia

$\mathrm{Y}$ a los sus dioses juraba

De matar al rey Tarquino

$Y$ de quemalle su casa.

En un monumento negro

90 El cuerpo a Roma llevaba,

Y púsola descubiera

En medio de una gran plaza.

De los sus ojos llorando.

De la su boca hablaba.-

95 ¡Oh romanos, oh romanos,

Doleos de mi triste fama 
Qu'el soberbio rey Tarquino

Ha forzado a esta romana!

Y por esta gran deshonra

100

Ella misma se matara.

Ayudadme a la vengar

Su muerte tan desastrada.-
Desque aquesto vido el pueblo

Todos en uno se armaban.

105

vanse para el palacio

Donde el rey Tarquino estaba,

Danle mortales heridas

Y quemáronle su casa.

2. Si partimos de la historia, tal como la transmitían Livio y Ovidio, observamos ciertas variantes en el romance.

2.1. Hay omisiones, puesto que se habla del amor de Tarquinio hacia Lucrecia sin decirse nada de cuándo empezó a surgir ese amor. Tanto Livio como Ovidio ofrecen las circunstancias en las que ocurrió; en el campamento, durante una guerra, que permitía demasiado descanso, los jóvenes príncipes hablan de sus esposas, alabando cada cual a la suya; Tarquinio Colatino, el esposo de Lucrecia, acude al mejor argumento, comprobar qué están haciendo durante su ausencia. Al ver a Lucrecia, hermosa y casta, el joven Tarquinio se enamora perdidamente de ella. El parentesco $0^{9}$ y esta visita explica que la segunda no cause sorpresa ni sospecha en Lucrecia.

2.2. También silencia el romance al padre de Lucrecia; ésta, tras sufrir violencia, envía mensajeros a su padre y a su marido, pidiéndoles que acudan inmediatamente acompañados cada uno de un amigo; el romance sólo habla del marido. Pese al dramatismo que aporta la figura de un padre ante los hechos que ocurren en la historia, era un personaje prescindible.

2.3. Hay ciertas confusiones, quizá deliberadas, fruto del deseo de condensar la historia en los elementos fundamentales; por ejemplo se atribuye al rey Tarquinio "la hazaña" del hijo. Esta "confusión" es coherente con la historia contada: el culpable debe morir; aquí se afirma que le dieron mortales heridas y le quemaron la casa. En el tratamiento "antiguo" sí asaltan y queman el palacio del rey (no del hijo), pero no lo matan ni muere, sino que "huye", como recuerda la fiesta celebrada por los romanos, la regis fuga. Pero, sin duda, la acción del hijo sirvió de desencadenante de la sublevación.

2.4. Un cambio fundamental se refiere al autor de la venganza; la historia transmite que, al pedir Lucrecia que acudiesen su padre y su marido, éste lo hace acompanado de Junio Bruto, pariente tanto del marido como del adúltero; este Bruto que, bajo la apariencia de la máxima estulticia, ocultaba una gran previsión, inteligencia y valor, toma la iniciativa. El romance ignora la figura de Bruto y atribuye la venganza al esposo de la víctima.

2.5. La especificación del color del esclavo no estaba en Livio, Ovidio, ni V. Máximo, pero en algún momento debió introducirse en la leyenda. La pintura de

9 El marido y el "amante", como se sabe, eran primos; son Tarquinios; el esposo es Colatino, por Colacia; el otro es apodado "Soberbio" como su padre. 
Botticelli sitúa junto a Tarquinio un personaje de color, que recuerda al esclavo del romance.

3. En cuanto a las semejanzas, las hay de diversa naturaleza, como trataremos de mostrar seguidamente al poner de relieve las deudas del romance -directas o indirectas- a los textos latinos que transmiten in extenso la historia. Ahora bien, el romance como obra literaria, independientemente de "sus fuentes", contiene unas características y virtudes dignas de mención, las cuales se perciben desde el mismo comienzo, que presenta ese "aire" de poema que narra asuntos lejanos $(C f$. "Aquel Rey de los romanos/ que Tarquino se llamaba").

4. Se divide el romance en tres grandes bloques, I, vv. 1-48, II vv. 49-80 y III, vv. 81-108), que acaban respectivamente con la violación, suicidio y muerte del rey. Cada uno de estos bloques o actos, se dividen a su vez en una serie de diferentes partes o escenas. En ellos las intervenciones de los protagonistas en estilo directo, de acuerdo con la naturaleza del tema y la condición de "romance", alternan con las partes narradas. Las intervenciones en estilo directo, que coadyuvan al dramatismo del relato (ciertamente se puede hablar de "actos") en el primer bloque suman 20 versos, en una "suerte de diálogo" entre Tarquinio y Lucrecia; en el segundo sólo habla Lucrecia, dirigiéndose a su marido, ocupando el parlamento 12 versos; en el tercero en ocho versos encontramos el "discurso-arenga" de Colatino al pueblo.

4.1. El primer acto (1-48) está dividido en cuatro partes de diez, diez, doce y dieciséis versos.

4.1.1. Versos 1-10. De ellos, los primeros seis, en que se habla de "aquel rey de los romanos/ que Tarquinio se llamaba", adelantan las notas fundamentales: Tarquino está enamorado de Lucrecia, quiere dormir con ella, y para ello prepara una "traición". El mundo de los sentimientos y el talante moral está ya ofrecido. Por contra, de Lucrecia se dice que es noble y casta, y la podemos observar en una situación desfavorable; está en peligro, acechada. En los cuatro versos siguientes (7-10), subdivididos también en dos, se completa la presentación de la escena: él marcha en secreto a donde está Lucrecia; ella, cuando lo ve en su casa, le ofrece excelente acogida. Estos versos ${ }^{10}$ están más cerca de Livio; el "namorose" (v. 3) y "para dormir con ella piensa una gran traición" (vv. 5-6) recogen lo dicho por el historiador", al transmitir los sentimientos del joven durante la primera visita que hacen todos a Lucrecia; en Livio estaba aludida la "violencia" (vis), "estupro" (mala libido Lucretiae...stuprandae); a forma y cas-

\footnotetext{
10 "Aquel rey de los romanos/ que Tarquino se llamaba/namorose de Lucrecia/ la noble y casta romana/y para dormir con ella/ una gran traición pensaba".

I) Cf.57, 10: Ibi Sex. Tarquinium mala libido Lucretiae per vim stuprandae capit; cum forma tum spectata castitas incitat.
} 
titas corresponden en el romance "noble y casta" (v.3)12. En los versos 7-813, "secretamente" quizá recoja la idea de inscius (inscio Collatino) de Livio I 58. Los versos 910 implican todo lo que hizo Lucrecia: acogerlo, aposentarlo como rey, y llevan a Livio 582 (exceptus benigne), o al comiter excipitur de Ovidio (v. 788) ${ }^{14}$; en ello se puede sobreentender todo lo que refieren los latinos, aunque lo silencie el romance ${ }^{15}$

4.1.2. Consta también de diez versos (11-20), sirviendo los seis primeros para ir centrando la acción, situada a media noche: se levanta Tarquino y va adonde Lucrecia duerme ("adonde Lucrecia estaba", v. 14, idéntico al verso 8), sin preocuparse de ninguna traición (ya de traición hablaba en el verso 6); los cuatro siguientes (17-20) focalizan los distintos momentos: llega junto a ella (17), desenvaina la espada (18), la sitúa cerca del pecho (19) y se dipone a hablar: "habla así" (20). En todo ello subyacen los textos clásicos ${ }^{16}$. "A hora de media noche" (v. 11) es similar a Ovidio 793: nox erat y "se levantaba" al surgit de 794. Los versos 13-2017 se detienen en el momento, con un mayor patetismo. Correspondencias existen en: "durmiendo" y dormientem de Livio; "aposento" $\mathrm{e}$ in thalamos de Ovidio; "de tal traición descuidada" evoca el nupta pudica de Ovidio; "desenvainó su espada", stricto gladio de Livio y vagina liberat ensem de Ovidio18; "a los pechos se la puso" se acerca a Livio (oprime el pecho con la mano izquierda); en Ovidio se habla de lecho (torum pressit).

4.1.3. Doce versos (21-32), divididos en tres subpartes de cuatro, integran esta sección; en la primera, Tarquinio se identifica ante Lucrecia como rey de Roma (2122) y como amante, al que el amor le traspasa el alma (23-24); en la segunda le ofrece

12 En Ovidio el apasionado amor de Tarquinio y los encantos de Lucrecia están recreados en un buen número de versos, 761-780: Interea iuvenis furiales regius ignes/ concipit et caeco raptus amore furit;/ forma placet niveusque color flavique capilli quique aderat nulla factus ab arte decor:/ verba placent et vox et quod corrumpere non est,/ quoque minor spes est, hoc magis ille cupit J lam dederat canius lucis praenuntius ales, cum referunt iuvenes in sua castra pedem/ Carpitur attonitos absentis imagine sensus/ille; recordanti plura magisque piacent:/ sic sedit, sic culta fuit, sic stamina nevit/ neglectae collo sic iacuere comaeJ hos habuit vultus, haec illi verba fueruns $/$ hic decor, haec facies, hic color oris erat $/ V i$ solet a magno fluctus languescere flatu sed tamen a vento, qui fuit, unda tumet// sic, quamvis aberat placitae praesentia formae/ quem dederat praesens forma, manebat amor; adet ef iniusti stimulis agitatus amoris/ comparat indigno vimque dolumque toro. En ellos. logicamente, están expresados (en negrita) los términos fundamentales : furiales ignes, forma, amor, vis, dolus, etc.

13 "Vase muy secretamente/a donde Lucrecia estaba".

14 Livio 58 1: Paucis interiectis diebus Sex. Tarquinius inscio Collatino cum comite uno Collatiam venit. Vbi exceptus benigne ab ignaris consilii cum post cenam in hospitale cubiculum deductus esset, etc. Ovidio $787 \mathrm{~s}$. es más escueto: hostis us hospes init penetralia Collatini:/ comiter excipitur: sanguine iunctus erat.

15 Ofrecerle la cena y locho.

16 Livio 58, 2, muy cercano, decía: (...) amore ardens posiquam satis tuta circa sopitique omnes videbantur, stricto gladio ad dormientem Lucretiam venit sinistraque manu mulieris pectore oppresso 'tace, Lucretia' inquir. Ovidio, por su parte, 791-95: Functus erat dapibus: poscunt sua tempora somnum;/ nox erat et sota lumina nulla domo;/ surgit et aurata vagina deripit ensem/ et venit in thalamos, nupta pudica, tuos:/ utque torum pressit... . .ait.

17 "Vase para su aposento/ adonde Lucrecia estaba/a la cual halló durmiendo/ de tal traición descuidada / En llegando cerca de ella/ desenvainó su espada/ y a los pechos se la puso. D'esta manera le habla".

18 En los latinos el hecho de desenvainar la espada es previo a la salida de su aposento; en el romance ocurre al legar junto a la mujer 
una disyuntiva: si cumple su voluntad será rica (25-26), si no, morirá (27-28); en la tercera aparece la reacción de Lucrecia, que afirma no estar dispuesta a hacer su voluntad aunque la mate (29-30), porque prefiere perder la vida a vivir sin honra (31-32). Los versos $21-28^{19}$ encuentran un eco en Livio, aunque éste es mucho más breve y contundente; sólo le dice que lleva una espada en la mano y que la matará si grita ${ }^{20}$.Ovidio más breve todavía, suprime la amenaza de muerte ${ }^{21}$. Así, aunque en los textos latinos estaba implícito, es el romance el que dice expresamente que la matará si no hace lo que el amante quiere. Los versos 29-32 del romance 22 dejan oir la voz de Lucrecia, lo que no ocurría en los textos latinos; ellos hablaban de obstinación, de silencio, de temor, de cómo el amante la insta con confesión de amor, súplicas, y por fin, con amenazas, pero frente a esto sólo el silencio por parte de la mujer. La segura proclamación de no querer vivir "deshonrada" hecha por Lucrecia refleja el espíritu valiente de la heroína del romance.

4.1.4. Los versos 33-48 representan la cuarta parte, la culminante en este primer acto del drama: la violación de Lucrecia. La escena está compuesta de dos subpartes desiguales, una, de doce versos (se podría hablar de tres estrofas), la segunda, sólo de cuatro versos o una sola estrofa, trasunto ésta de la rapidez con que ocurrió todo y el deseo de no detenerse el narrador a dar detalles de un momento tan trágico. En la primera, pues, Tarquinio piensa en otra "traición" (33-36); la amenaza con matarla y con ella a un esclavo (37-40), ponerlos juntos en la cama y decir por toda Roma que allí los tomó (41-44); en la segunda, en cuatro versos, da cuenta de que ella, al oirlo, cumplió su voluntad para no ser tan deshonrada (45-48). Los textos latinos están igualmente detrás de los versos 33-4423. Livio hablaba de que añadió al miedo que ella tenía la amenaza de deshonrarla (dedecus) diciendo que pondría junto a ella muerta a un esclavo (nudus servus) también asesinado, como si la hubiese sorprendido en adulterio (adulterium) 24 ; Ovidio en otros términos dice cosas semejantes, habla de adulterio, de un famulus, de que se dirá que con él ha sido sorprendida.25 El romance, como en Ovidio, lo expresa en estilo directo, pero la palabra "traición" parece llevar a dedecus

19 "Yo soy aquel rey Tarquino/ Rey de Roma la nombrada; el amor que yo te tengo/ las entrañas me traspasa:/ Si cumples mi voluntad/ serás rica y estimada: si no, yo te mataré/ con esta cruel espada".

20. 58, 2: "Sex Tarquinius sum: ferrum in manu est; moriere, si emiseris vocem". Sin embargo, Livio ya habia hablado de su amor, de cómo sale Tarquinio de su alcoba, amore ardens.

21 v. 795-796: Vique torum pressit, "Ferrum, Lucretia, mecum esi'/ natus ait regis, Tarquiniusque vocor' (en otros mss: loquor).

22 "Esto no hare yo, oh Rey/si la vida me costara; que más la quiero perder/ que no vivir deshonrada".

23 "Como vido el rey Tarquino/ que la muerte no bastaba/ acordó d'otra traición;/ con ella la amenazaba/-Si no cumples mi deseo/ como yo te lo rogaba/ yo te mataré, Lucrecia/ con un negro de tu casa/y desque muerto lo tenga/ echarlo he en la tu cama;/ yo diré por toda Roma/ que a ambos juntos os tomara".

24 58, 4: Vbi obstinatam videbat et ne mortis quidem metu inclinari, addit ad metum dedecus: cum mortua iugulatum servum nudum positurum ait, ut in sordido adulterio necata dicatur.

25807 ss.: "Nil agis: eripiam" dixit "per crimina vitam:/ falsus adulterii testis adulter erit:/ interimam famulum, cum quo deprensa fereris". 
de Livio, como también subyace en el romance ubi obstinatam videbat.., etc.; el romance interpreta el significado de dicatur o fereris: será Tarquinio en persona quien lo va a decir por toda Roma; hay también gran minuciosidad en la referencia a los distintos momentos de la acción que proyecta Tarquino (matar, echar a la cama etc.). Los versos $45-48$ ofrecen la violación en términos precisos y escuetos ${ }^{26}$, de manera similar a Ovidio ${ }^{27}$, que en un sólo verso explica que el temor a la "fama" ("por no ser tan deshonrada", dice el romance) hizo sucumbir a la mujer (victa); Livio se servía del mismo verbo vinco para pintar la pudicitia de Lucrecia, vencida, y hablaba de terror como Ovidio lo hacía de metus.

Llevada a cabo la violación acaba el primer bloque o, como decíamos, el primer acto.

4.2. El segundo bloque ocupa los versos 49-80. En este acto ha salido ya de escena Tarquinio y entrará el esposo de Lucrecia, aunque lo hará como personaje "mudo". Culminará, como hemos recordado, con el suicidio de la mujer. Se divide en tres partes de diez, catorce y ocho versos.

4.2.1. Diez versos (49-58) constituyen la transición entre el primer y segundo bloque y en ellos se contempla la reacción de los "protagonistas" de la historia: Tarquinio marcha contento y alegre, ella queda triste y deshonrada, y envía a llamar a su marido que estaba ausente, en Roma. La alegría de Tarquinio expresada en los versos 49-5228 estaba en Ovidio que, dirigiéndose a él le dice: quid, victor, gaudes? (v. 811); Livio sólo manifiesta que se marchó ferox. Los versos 53-5829 nos pintan a Lucrecia triste al verse, insiste el romance, tan deshonrada, y cuentan cómo envía a llamar a su marido. La pintura de Livio era similar, aunque en él los llamados son el padre y el esposo, que estaban en lugares diferentes ${ }^{30}$; las semejanzas son patentes ${ }^{31}$. Ovidio al contemplarla sentada con los cabellos sueltos, y compararla con una madre que va a enterrar a su hijo ${ }^{32}$, sugiere lo mismo 33 .

4.2.2. Consta este pasaje de catorce versos (59-72); la presentación del marido

26 "Después qu esto oyó Lucrecia / que tan gran traición pensaba / cumpjióle su voluntad/ por no ser tan deshonrada".

27. 810: succubuit famae victa puella metu.

28 "Cuando Tarquino hubo hecho/ lo que tanto deseaba / muy alegre y muy contento/ para Roma se tomaba".

29 "Lucrecia quedó muy triste/ en verse tan deshonrada:/ Enviara muy aprisa/ con un siervo de su casa/ a llamar a su marido/ porque allá en Roma se estaba".

30 58.5: Lucretia maesta tanto malo nuntium Romam eundem ad patrem Ardeamque ad virum mittif, ut...veniant.

31 Hay, sin embargo, una diferencia: el padre es el que está en Roma, en Ardea su marido. El romance pone al marido en Roma y, como hemos dicho ya, omite la mención del padre.

32813 ss.: iamque erat orta dies: passis sedet illa capillis./ ut solet ad nati maser itura rogum,/ grandaevumque patrem fido cum coniuge castris/ evocat. En Livio padre y marido encuentran a Lucrecia también "sentada" y triste.

33 Ovidio, como Livio, alude al padre y al marido. 
está en dos (59-60); en los doce siguientes (61-72) le relata lo ocurrido, y le comunica su decisión: Comienza con una exclamación de cariño (" $; O \mathrm{Oh}$ mi amado Colatino!") y le informa de la pérdida de su fama; de que su cama ha sido hollada por hombre ajeno (61-64); identifica al autor (el soberbio rey Tarquino), al que recibió como rey (cf. v. 10), y que la dejó violada (65-68); le comunica que se infringirá el castigo que corresponde a las adúlteras (69-70) para que ninguna matrona pueda ser mala siguiendo su ejemplo (71-72). Estos versos 59-7234 están impregnados de un enorme movimiento. Sin que nada se sepa del marido, a no ser que ha venido, y que lo ha visto la esposa, comienza la alocución de Lucrecia, que, sin esperar palabra alguna ni reacción de ninguna clase, narrará los hechos y expondrá sus planes. En Livio y Ovidio, sin embargo, se introduce esta escena con los pertinentes llantos, con las preguntas que se le formulan ${ }^{35}$ a la mujer, aunque el tratamiento en ambos es diferente. Con todo, el romance está muy cerca de Livio; también en éste comenzaba Lucrecia confesando la pérdida de su honor ${ }^{36}$, y aludía a las "huellas" (vestigia) de otro hombre, un hombre ajeno, no dueño del lecho, vestigia, que el romance interpreta como "pisadas" 37 . Omite sin embargo el romance un breve excurso sobre la dualidad alma/cuerpo y el cómo es culpable el cuerpo pero inocente el alma, y que donde no hay consentimiento no hay culpa, etc. Omite también cómo la mujer les hace jurar que castigarán al culpable, pero coincide con Livio, aunque no hace confesión de su inocencia, en que ninguna mujer adúltera podrá usar en su beneficio el ejemplo de Lucrecia ${ }^{38}$.

4.2.3. Ocho versos (73-80) tratan el suicidio de Lucrecia; ella, mientras habla, saca la espada oculta 73-76), se la pone al pecho -oímos la voz del poeta que reacciona ante el espectáculo (que lástima era mirarla, v. 78) y allí y entonces cae muerta (7780). Este pasaje ${ }^{39}$ reproduce lo dicho por Livio ${ }^{40}$ y Ovidio ${ }^{41}$, aunque ellos insistían en

34 "Cuando ante s( lo vido/ d'esta manera le habla/ $-i$ Oh mi amado Colatino!/ Ya es perdida la mi fama/ que pisadas de hombre ajeno/ han hollado la tu cama/ El soberbio Rey Tarquino/ vino anoche a tu posada/ recibile como á rey/y dejóme violada/ Yo me daré tal castigo/ como adúltera malvada/ porque ninguna matrona/ por mi ejemplo sea mala".

35 Ovidio (819-828) insiste en que ella intentaba hablar, aunque no podia: no nara los hechos, se limita a hablar de dedecus y a llorar.

36 58, 7: Al verla llorando (Adventu suorum lacrimae oborae) y preguntarle el marido si estí bien (quae. rentique vim 'Satin salve'?) ella contesta."No" ('Minime, inquit, 'Quid enim salvi est mulieri amisso pudicitia?').

37 58, 7: Vestigia viri alieni, Collatine, in lecto sunt tuo.

38 58, 10: ego me etsi peccato absolvo, supplicio non libero; nec ulla deinde impudica exemplo Lucretice vivet. Ponerla de ejemplo significa, obviamente, poner de excusa el "haber sido forzada" decir que "ha sido forzada": tanto en Livio como en Ovidio son padre y marido quienes la consideran inocente por haber sido "coaccionada". En Ovidio, a la venia condecida por el padre y esposo respondfa Lucrecia (v. 830): 'Quam'dixil "veniam vos datis, ipsa nego".

39. Versos 73-80: "Estas palabras diciendo/ echa mano de una espada/ que muy secreta tráa/ debajo de la su hajda / y a los pechos se la pone / que lástima era mirarla / Luego allí en aquel momento/ muerta cae la romana.

40. Tras manifestar Lucrecia su decisión de morir añade $(58,11)$ : Cultrum, quem sub veste abditum habebat. eum in corde defigit, prolapsaque in volnus moribunda cecidit.

41. Vv. 831-832: nec mora, celato fixit sua pectora ferrol et cadit in patrios sanguinulenta pedes. 
que padre y esposo le ofrecen un perdón que ella no acepta ${ }^{42}$.

Llegado a su punto álgido el segundo acto con el suicidio de Lucrecia, comienza el tercero y último.

4.3. Ocupa este bloque los versos 81-108, veintiocho versos; ahora el protagonista es el esposo (ausente en el primero y espectante y mudo en el segundo), seguido luego del pueblo, movido por él. Se desarrolla en tres escenarios (casa de Lucrecia, Foro y palacio de Tarquinio), y consta de cuatro partes de ocho, cuatro, diez y seis versos.

4.3.1. Los versos (81-88) tienen por escenario la casa de Lucrecia. El marido llora al verla muerta, le saca la espada de su pecho (vv. 81-84) y con ella en la mano jura vengarse (85-88) ${ }^{43}$. Representan, pues, la reacción del marido, sólo él (no se alude ni a amigos ni a suegro) ${ }^{44}$. En Livio ${ }^{45}$ lloran padre y marido y, mientras, Bruto extrae la espada y jura perseguir a sangre y fuego al rey Tarquinio y a toda su familia; después juran todos y siguen a Bruto como jefe. Ovidio repite más brevemente los hechos narrados por el historiador y habla claramente de huida; no en balde se celebra la "fuga del rey" 46 .

4.3.2. Cuatro versos (89-92) $)^{47}$ narran el traslado del cadáver a Roma; allí colocan a Lucrecia descubierta, en medio de la plaza. Livio hablaba del "foro", pero no de Roma ${ }^{48}$.

4.3.3. En los versos 93-102 aparece el discurso de Colatino, en la gran plaza, junto al cuerpo de la esposa; lo introducen dos versos (93-94) que hablan de su estado de ánimo; consta de tres partes de dos, cuatro y dos versos respectivamente, y está dirigido al pueblo ${ }^{49}$. Comienza llamando a los romanos a dolerse de su fama (95-96); les

42. Livio 58 9: consolantur aegram animi avertendo noxam ab coacta in auctorem delicti: mentem peccare, non corpus et unde consilium afuerit, culpam abesse. Ovidio 829: Dant veniam facto genitor coniunxque coacto.

43. "Su marido que la vierta/ amargamente lloraba:/ sacóle de aquella herida/ aquella sangrienta espada/ Y en su mano la tenia/ y a los sus dioses juraba/ de matar al rey Tarquino/ y de quemalle su casa".

44. $L a$ idea de matar y quemar la casa quizá derive de lo que dice en Livio 59 Bruto (lestes facio me $L$. Tarquinium ... ferro igni quacumque dehine vi possim execururum. etc.

45.59. 1: Brutus illis luctu occupatis cultrum ex vulnere Lucretiae extrachum manantem cruorem prae se tenens. 'per hunc'inquit 'cassissimum ante regiam iniuriam sanguinem iuro vosque. dii, testes facio me L. Tarquinium Superbum cum scelerata coniuge et omni liberorum stirpe ferro. igni. quacumque dehinc vi possim. execusurum nec illos nec alium quemquam regnare Romae passurum".

46. 837-844: Brutus adest tandemque animo sua nomina fallit/fixaque semanimi corpore tela rapit/ stillantem. que tenens generoso sanguine cultrum/ edidit impavidos ore minante sonos:/ 'Per tibi ego hunc iuro forsem castumque cruorem/ perque suos manes, qui mihi numen erunt/ Tarquinium profuga poenas cum stirpe daturumJ lam satis est virtus dissimulata diu".

47. "En un monumento negro/ el cuerpo a Roma llevaba/ y púsola descubierta/ en medio de una gran plaça".

48. 59, 3: Elatum domo Lucresiae corpus in forum deferuns.Livio, sin embargo, hablará luego de Roma (cf. $\mathrm{n}$. 53).

49. Vv. 93-102: "De los sus ojos llorando/de la su boca hablaba / "Oh romanos, oh romanos/doleos de mi triste fama/ qu'el Soberbio rey Tarquino/ ha forzado a esta romana!/ $Y$ por esta gran deshonra/ ella misma se matara/ Ayudadme a la vengar/ su muerte tan desastrada"”. 
comunica la violación y el suicidio al que ella fue obligada (97-100); acaba pidiendo ayuda para vengar su muerte (101-102). El discurso, que no constaba en los textos clásicos, se limita a repetir lo que la esposa le había confesado; antes, pide compasión y, luego, ayuda para la venganza ${ }^{50}$.

4.3.4. Seis versos (103-108) tratan la reacción del pueblo ante el espectáculo y el discurso: se arman a una, marchan a palacio, hieren al rey y le queman la casa ${ }^{51}$. En Livio, los mueve tanto la tristeza del padre como la figura de Bruto, el responsable de que tomen las armas contra los Tarquinios 52 . Ovidio por su parte, como corresponde a la naturaleza de su obra, concluye rápidamente, en tres dísticos, que resumen los datos fundamentales: exequias, convocatoria de Bruto y huida del rey y su familia ${ }^{53}$. El romance, pues, acaba con la reacción de un pueblo que, por otra parte, ya tenía motivos para sublevarse, pero ha cambiado los datos; es más contundente, y más esperable como castigo, una muerte que una huida. Es más lógico que el marido asuma el protagonismo, y sea suya la iniciativa de vengar el ultraje de la esposa. Es, independientemente de la verdad de la historia legendaria, más dramático y efectista. El autor anónimo lo prefirió.

5. Y por fin concluimos. El romance, pese a las pequeñas modificaciones -voluntarias, sin duda, las más- que hemos ido mostrando a lo largo de estas páginas, además de mantener el tono poético, pondera los valores significativos de la historia; es un ejemplo de transmisión y pervivencia de una tema clásico que ha recorrido un largo trayecto. Pero en él reconocemos a Livio y a Ovidio, y también a un poeta que ha sabido captar ese tema, hacerlo suyo y recrearlo.

5.1. Los personajes están perfectamente retratados: el amor, la pasión, la prisa que tiene Tarquinio en llevar a cabo su "hazaña", sus innobles sentimientos; son elocuentes pinceladas; no es casualidad que la palabra "traición" aparezca muy pronto y luego se repita (cf. versos $6,16,35,46$ ), o el que, junto a su confesión de amor, esté, acto seguido, la amenaza de muerte (23-24 y 27-28), para insistir luego en otras amenazas peores, y sobre todo para marchar "alegre y contento"; el retrato, pues, aprovechando los datos que suministraba la historia, ha sido reelaborado por el autor del romance de modo oportuno y artístico.

50. Bruto era quien de otro modo la había pedido en Livio u Ovidio.

51. Vv. 103-108: "Desque aquesto vido el pueblo/ todos en uno se armaban $/$ y vanse para el palacio/ donde el rey Tarquino estaba/ danle mortales heridas/ y quemáronle su casa".

52. 59, 4: Movet cum patris maestitia, tum Brutus castigator lacrimarum atque inertium querellarum auctorque, quod viros, quod Romanos deceref, arma capiendi adversus hostilia ausos. Livio seguirá narrando (capítulos 59 y 60) la reacción de las gentes. recordando la historia y los crímenes de la familia real y la venganza que dará lugar al fin de la Monarquía y el nombramiento de los cónsules.

53. 847-852: Fertur in exequias animi matmona virilis/ et secum lacrimas invidiamque trahit:/ vulnus inane patet: Brutus clamore Quirites/ concitat et regis facta nefanda refert; Tarquinius cum prole fugit: capit annua consull iura: dies regnis illa suprema fuit. 
5.2. También la pintura de Lucrecia es adecuada: casta y noble ( $v .4)$, cumpliendo los deberes de la hospitalidad (v.10), durmiendo tranquila y descuidada (vv. 16-17), pero valiente, dispuesta a morir antes de ser deshonrada (vv. 31-32), y que para no serlo sucumbe a la voluntad del adúltero (v. 48); su valentía no sólo le hace llamar a su marido, sino contarle ella misma -más que en Livio- lo que había ocurrido, y su resolución y diligencia (exigida por el romance, quizá) para "matarse" sin esperar un instante.

5.3. El discurso del marido, que no contaba con antecedentes en los textos clásicos, está decorosamente construido y es idoneo al contexto; el "doleos" (v. 96) con que comienza, después de repetir dos veces la palabra "romanos," y el "ayudadme a la vengar" ( $v .101)$ presentan los imperativos que tienden a cambiar la voluntad del pueblo y a hacerlo actuar.

5.4. La acción es rápida, todo ocurre en menos de veinticuatro horas, parece responder a la "aristotélica ley del tiempo".

5.5. El tema, como otros griegos y romanos, de la historia o mitológicos, podía ser llevado al romance; el romance, con el verso octosílabo y la rima asonante, con el léxico y, sobre todo, la fraseología, ha aportado a la historia una nueva veste, en absoluto indigna; la historia ha sido estructurada artísticamente usando los recursos narrativos y poéticos; se ha producido una vez más un caso de intercambio y colaboración entre el mundo clásico y el que vino después. 